\title{
Bioreactor Culture Biosynthesis
}

National Cancer Institute

\section{Source}

National Cancer Institute. Bioreactor Culture Biosynthesis. NCI Thesaurus. Code C112958.

A process that synthesizes a material of interest using a large scale cell culture that is grown in a bioreactor. 